\title{
Ueber das ätherische Oel der virginischen Ceder, Juniperus virginiana;
}

von

Bonastre.

(Journ. de Pharmacie XXIII. 177.)

Die Zusammensetzung der ätherischen Oele bietet ohnerachtet der Untersuchungen der Chemiker noch manche Schwierigkeiten dar, die auch durch die genaueste Elementaranalyse noch nicht beseiligt werden. Die ätherischen Oele werden durch Rectification gereinigt, in diesem Zustande können sie aber noch oft aus mehren verschiedenen Principien bestehen, die zugleich mit einander überdestilliren.

Nach meinen Untersuchungen über die Harze hatte ich die Ansicht gewonnen, dass auch die ätherischen Oele, welche sie enthalten, ein krystallisirbares Princip zurückhalten. Dieser Art ist die krystallinische Materie, die sich im 'Terpentinöl bildet, und die ich noch besilze. In ihrer Krystallisation hat sie die grösseste Aebnlichkeit mit der, die man in dem Terpentin der Pinien und Melezeen gefunden, und Abietin oder Laricin genannt hat, und die vielleicht der Sylvinsäure analog ist.

Zur Untersuchung meiner Ansicht glaubte ich durch Destillation eines Harzes das ätherische Oel desselben mit seiner krystallinischen Materie zu erhalten. Da das Amyrin des Elemi leicht krystallisirt, so stellte ich mit dem Elemi Versuche an, aber sey es, dass das Amyrin zu fixirt, oder dass es von dem Harze mit zu grosser Kraft zurückgehalten wird, meine Versuche gaben ein negatives Resultat, und das ätherische Oel des Elemi gab, der Luft ausgesetzt, keine besondere krystallinische Materie, so wenig das rectificirle als das nicht rectificirle. 
Im vorigen Jahre habe ich einige Versuche mit dem Oele von Juniperus virginiana angestellt, aus welchem ich selbst bei $+5^{\circ} \mathrm{R}$. eine in Alkohol lösliche krystallinische Materie erhielt.

Das Holz der Virginischen Ceder wird jelzt sehr viel gebraucht, besonders auch zum Einfassen der Bleislifte. Der eigenthïmliche angenelsme Geruch des Holzes hat veranlasst, las ätherische Oel daraus darzustellen.. Ueber dieses Oel theile ich Nachstehendes mit.

8o Pfund des geraspellen Holzes werden mit der nöthigen Menge Wasser destillirt. .Das Oel geht leicht über, es ist im Allgemeinen dicklich, schwimmt auf dem Wasser und beträgt aus obiger Holzmenge 5o Unzen.

$\mathrm{Da}$ dieses Oel ungleich dicklich ist, oft auch Körnchen darin sich zeigen, so schmilzt man es gewöhnlich in gelinder Wärme und filtrirt es. Es erscheint darauf flïssig, homogen von einer etwas dicklichen Consistenz, aber vor dem Schmelzen war es fast fest.

Bei dem Versuch, die krystallinische Materie daraus darzustellen, selzle ich $3_{2}$ Gramm. des Oels einer Källe von $-7^{\circ}$ R. aus, zu meinem Erstaunen aber wurde es nicht dicker als es bei $10^{\circ} \mathrm{R}$. war. Zur Erforschung dieses auffallenden Verhaltens wurden folgende Versuche angestellt.

1) In mehre kleine trockne Becher gab ich etwas des Oels, einige derselben setzte ich der Luft aus, während ich die übrigen $z u$ andern Versuchen bewahrte.

2) Einen dieser Becher, der 4 Gramm. des noch flüssigen Oels enthielt, olnerachtet es einer Temp. von $-7^{\circ} \mathbf{R}$. ausgesetzt gewesen war, setzte ich am 3.-Febr. $183_{7}$ der freien Luft aus. Am 15 ten schien eine Sonderung in dem Oele sich zu bilden und der untere Theil dicker zu seyn, als der obere. Am 2osten waren beide Theile fast völlig 
fest, und bier und da bemerkte man Krystalle oline Consistenz darin. Die Temp. der Luft war in dieser Zeit zwischen o bis $+10^{\circ} \mathrm{R}$.

3) Etwas des fraglichen flüssigen Oels gab ich in einen trocknen Becher, und dazu eine sehr kleine Menge der festen Materie. Die Becher wurden hermetisch verschlossen. Die Temp. war zwischen +5 und $+8^{\circ} \mathrm{R}$. Am folgenden Morgen war das ganze Oel erstarrt. Die Wiederholung des Versuchs gab dasselbe Resultat.

Unter den beīnerkten Umständen hatte also ein Atom einer krystallinischen Materie hingereicht, dass das flüssige Oel fest wurde, was eine Temperatur-Differenz von $17^{\circ} \mathrm{R}$. nicht zu bewirken im Stande gewesen war. Luft und Wasser hallen beide keinen Einfluss auf dieses Resultat haben können.

Ich weiss nicht, ob dieses Verhalten sich auch anf andere flüssige Oele ausdelnt, die eigenthümliche krystallinische Materie enthalten, oder in denen solche sich bilden; wenn es aber so ist, so wird es vielleicht einiges Licht auf die organische Chemie werfen, wo die Erscheinungen nicht immer leicht zu erklären, noch unter gegebenen Umstän. cen hervorzubringen sind.

\section{Analyse mehrer kleinen Concretionen, die sich im Oesophagus einerSchlange fanden;}

vom

$$
\begin{aligned}
& \text { Geh. Hofr. Wurzer } \\
& \text { in Marburg. }
\end{aligned}
$$

Die Schlange (Boa constrictor) war 12 Fuss lang. Die Coneretionen warer eckig, rauh, wie grober Sand und fanden sich zerstreut im ganzen Oesopbagus bis zu 